\title{
Ordinary differential equations for the dynamic characteristics of heating boilers
}

\author{
Sergei Khaustov ${ }^{1, *}$, Olga Guk ${ }^{1}$, and Igor Razov ${ }^{2}$ \\ ${ }^{1}$ National Research Tomsk Polytechnic University, 634050 Tomsk, Russia \\ ${ }^{2}$ Tyumen industrial University, 625003 Tyumen, Russia
}

\begin{abstract}
The paper presents ordinary differential equations for the dynamic characteristics of a solid fuel boiler that can be combined into onedimensional nonstationary mathematical model for simulating long-term dynamics of a solid fuel boiler. This model requires less computational time for a qualitative simulation of boiler's operation than known CFD-solutions. The long-term dynamic model presented can help to determine annual costs, to set up automatic control systems and to detect dangerous deviations in the project.
\end{abstract}

\section{Introduction}

With the development of computer technology, mathematical models have become widely used. These models enable us to correct technical decisions even while the design. Highly detailed CFD-models (Computational Fluid Dynamics) in a steady state [1-7] are the most commonly used method for heating boiler gas-dynamics evaluation. However, the thermal load on heating boilers varies considerably throughout the year followed by the changes of outdoor temperature [8-10]. In addition, during the long-term operation of solid fuel boilers, the fuel characteristics generally change, which also requires an adjustment of the operating mode $[8,11]$. Detailed CFD modeling of physical processes requires obtaining a stable solution of a system of complex differential equations by a resource-intensive finite element method [12-14]. It makes CFD models ineffective in solving practical-oriented non-steady-state heat exchange problems at long time intervals [15].

In general, the dynamic characteristics are the dependence of the change in time of productivity and efficiency of the boiler when it is varied by the regime parameters [16]. Dynamic simulation is practically used to determine the dynamic characteristics of the boiler $[8-10,15,17,18]$. The aim of this paper is to develop and present practically applicable equations for the dynamic characteristics of heating boiler.

We failed to find any mathematical models for simulating long-term dynamics of a solid fuel boiler. However these models can be useful for determining annual costs depending on meteorological and technological features. Moreover the long-term dynamic model of a boiler can help to set up automatic control systems and to detect dangerous deviations in the project $[4,18]$.

\footnotetext{
*Corresponding author: khaustovsa@tpu.ru
} 


\section{Mathematical apparatus}

Suppose that there is a diffusion combustion regime and the reaction rate is controlled by changing the inlet pressure. Let's denote: $F$ is the area $\left(\mathrm{m}^{2}\right)$ of the grate on which the fuel is combusted, $\mathrm{m}$ is the mass $(\mathrm{kg})$ of fuel on the grate at an arbitrary time $t$. As already noted, $m$ is a variable that varies in proportion to the flow rate of the combustion air. The amount of fuel consumption that determines the boiler's thermal output is the first derivative of $m$ in time $t$ :

$$
\dot{m}=\frac{\partial m}{\partial t}
$$

The heat output of a hot-water boiler is usually defined as the amount of heat $(\mathrm{kW})$ transferred to the coolant (water) during the combustion. According to the known values of the calorific value of fuel $Q(\mathrm{~kJ} / \mathrm{kg})$ and the efficiency of the boiler, this amount of heat $(\mathrm{kW})$ can be estimated as:

$$
P=Q \cdot \eta \cdot \dot{m}
$$

However due to the thermal inertia during transient operation of a boiler, the amount of heat transferred to the consumer differs from this value:

$$
P=\dot{m}_{w} \cdot c_{w} \cdot\left(T_{\text {out }}-T_{\text {in }}\right),
$$

where $m_{w}$ - mass flow of boiler water $(\mathrm{kg} / \mathrm{s}), c_{w}$ - specific heat of water $\left(\mathrm{kJ}^{\circ} \mathrm{kg}^{-1} \cdot \mathrm{K}^{-1}\right)$, Tout and $T_{i n}$ - temperatures of direct and reverse supply water, respectively, ${ }^{\circ} \mathrm{C}$.

The filtration rate - the air flow per second referred to the total cross-sectional area of the layer - is often used in investigations of layer combustion. Using this concept, we write the volumetric air flow, where $\omega$ is the average filtration rate at an arbitrary moment of time $t, \mathrm{~m} / \mathrm{s}$. The fuel consumption $(\mathrm{kg} / \mathrm{s})$ will be written by the equation:

$$
\dot{m}=\frac{F \cdot \varpi}{V_{0} \cdot \alpha} .
$$

The process of coal burning on the grate is controlled with forced and induced draft fans. The control parameters are the air pressure in the discharge air duct and the pressure of the flue gases behind the boiler $(\mathrm{Pa})$. It is possible to control the sum of the pressure losses in the gas and air tracts of the boiler $(\mathrm{Pa})$ :

$$
p_{\text {in }}-p_{\text {out }}=\Delta p_{g}+\Delta p_{w} .
$$

Let us express the pressure loss in the air path through the average velocity of filtration with the Darcy-Weisbach equation:

$$
\Delta p_{w}=p_{\text {in }}-p_{\text {out }}-\Delta p_{g}=(\zeta+\lambda \cdot \delta) \frac{\varpi^{2} \rho_{w}}{2}
$$

where $\omega$ is an average filtration rate, $\rho_{w}$ is an air density, $\mathrm{kg} / \mathrm{m}^{3}$, and $\zeta$ is an pressure loss coefficient, $\lambda$ is the drag coefficient of the layer, $m^{-1} ; \delta$ is the thickness of the coal layer (m) at an arbitrary time $t$ : 


$$
\delta=\frac{m}{\rho_{c} \cdot F}
$$

where $\rho_{c}$ is a coal density.

Expressing the value of the filtration rate from formula (2) and substituting it in (1), we obtain the final formula for fuel consumption:

$$
\dot{m}=\frac{F \cdot \sqrt{\frac{2}{\rho_{w}} \cdot \frac{p_{\text {in }}-p_{\text {out }}-\Delta p_{g}}{\zeta+\lambda \cdot \delta}}}{V_{0} \cdot \alpha}
$$

Despite the assumption (1), the analytical solution of equation (3) is a complicated problem because of its nonlinearity. The most universal and simple numerical method for solving ordinary differential equations is the Euler method. According to this method, we replace the derivative entering into equation (3) with a finite difference analogue in such a way that the time axis is sampled at intervals within which the fuel consumption is assumed constant.

To simulate the possible unevenness in the thickness or density of the coal layer, it can be sampled at $\mathrm{N}$ sections with a fuel mass $\mathrm{m}_{\mathrm{i}}$ and a lattice area $\mathrm{F}_{\mathrm{i}}$, where the index $i$ is the number of the section in the range 1.N. The passage cross-section of the $\mathrm{H}_{\mathrm{i}}$ lattice can also be set unevenly, which makes it possible to model the burning of coal on complex geometry grates:

Air flowrate:

$$
\sum_{i=1}^{N} F_{i} \cdot \varpi_{i}
$$

Fuel massflow:

$$
\sum_{i=1}^{N} \dot{m}_{i}
$$

$$
\dot{m}_{i}=\frac{F_{i} \cdot \sqrt{\frac{2}{\rho_{w}} \cdot \frac{p_{\text {in }}-p_{\text {out }}-\Delta p_{g}}{\zeta_{i}+\lambda \cdot \delta_{i}}}}{V_{0} \cdot \alpha}
$$

This approach enables us to predict the distribution of air filtration rates and coal burnup in a layer and simulate changes of the layer geometry in time (Fig. 1).

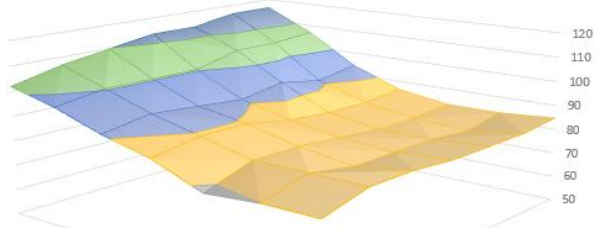

a)

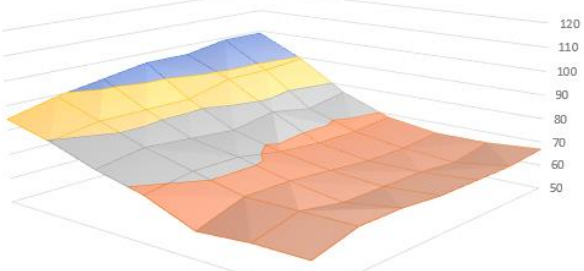

b)

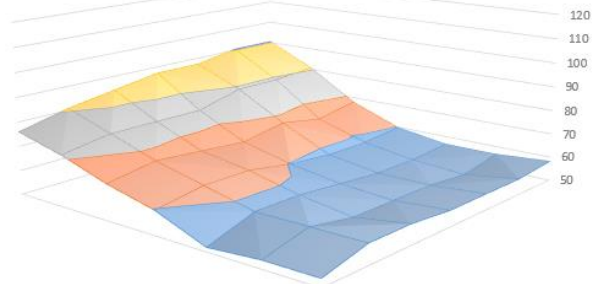

c)

$\square$ 50-60 $\square$ 60-70 $\square 70-80 \square$ 80-90 $\square 90-100 \quad \square 100-110 \quad \square 110-120$

Fig. 1. Coal layer (mm) thickness distribution at different time points: a) start up; b) after 30 minutes; c) after one hour. 
The rate of filtration and the burning rate of fuel (Fig. 2) are redistributed in inverse proportion to the drag of parallel sections. Even with a slight unevenness in the thickness or density of the coal layer, it burns down in places of least drag, tending to form sections without fuel - craters. The formation of craters, in turn, leads to a useless breakthrough of the air into the furnace through the bare sections of the grate. At the same time, the filtration rate sharply decreases through the areas covered with a layer of coal.

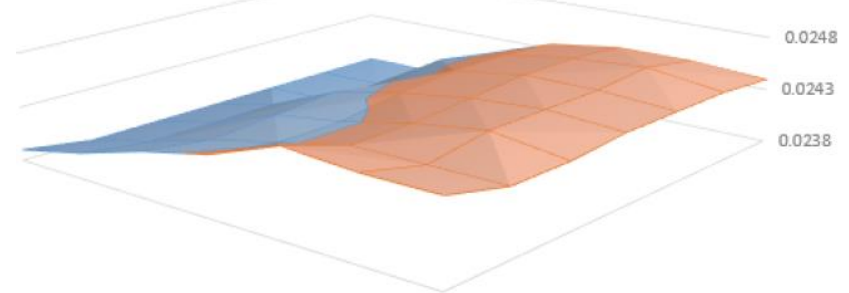

Fig. 2. Coal burning rate $\left(\mathrm{kg} \cdot \mathrm{s}^{-1} \cdot \mathrm{m}^{-2}\right)$ distribution.

According to the known values of the calorific value of the fuel $Q(\mathrm{~kJ} / \mathrm{kg})$ and the efficiency of the boiler, the amount of heat $(\mathrm{kW})$ that is transferred to the coolant during the combustion of the fuel can be written as

$$
Q \cdot \eta \cdot \sum_{i=1}^{N} \dot{m}_{i}
$$

In order to take into account the thermal inertia of the boiler's water volume, we assume that it has an average temperature $T_{\text {out }}$. Then from the coolant heat balance equation we write the expression how $T_{\text {out }}$ changes in time:

$$
\frac{\partial T_{\text {out }}}{\partial t}=\frac{Q \cdot \eta \cdot \sum_{i=1}^{N} \dot{m}_{i}+\dot{m}_{w} \cdot c_{w} \cdot\left(T_{\text {in }}-T_{\text {out }}\right)}{m_{w} \cdot c_{w}}
$$

where $m_{6}$ is the mass of water in the boiler, $\mathrm{kg}$.

\section{Conclusion}

Given ordinary differential equations for the dynamic characteristics of a solid fuel boiler can be combined into one-dimensional nonstationary mathematical model of the fire-tube boiler. This model requires less computational time for a qualitative simulation of boiler's operation than known CFD-solutions. With the Euler method the proposed model can be easily applied to solve engineering problems.

At the design stage, the dynamic model of the boiler is indispensable for detecting dangerous deviations in the heat engineering characteristics of fuel and operating parameters, as well as for the development and adjustment of automatic control systems. In addition, the dynamic characteristics of the boiler are decisive in the development of various simulators for training operators and boiler room staff.

\section{References}

1. H. Kim, S. Choi, Int. Commun. Heat Mass. 32, 786 (2005)

2. P. J. Coelho, P. A. Novo, M. G. Carvalho, J. Super Comput. 13, 211 (1999) 
3. A. A. Bhuiyan, J. Naser, Fuel 159, 150 (2015)

4. S. A. Khaustov, Y. A. Belousova, K. V. Buvakov, A. Y. Dolgih, R. N. Kulesh, 11th International Forum on Strategic Technology (IFOST - 2016) Proceedings 2, 548 (2016)

5. S. A. Khaustov, A. S. Zavorin, K. V. Buvakov, N. A. Zakharushkin, MATEC Web Conf. 19, 01020 (2014)

6. S. A. Khaustov, A. S. Zavorin, K. V. Buvakov, L. D. Kudryashova, A. V. Tshelkunova, EPJ Web Conf. 82, 01041 (2015)

7. S. A. Khaustov, A. S. Zavorin, K. V. Buvakov, V. A. Sheikin, EPJ Web Conf. 82, 01039 (2015)

8. S. A. Khaustov, O. V. Khaustova, A. N. Ermolaev, Bulletin of the Tomsk Polytechnic University. Geo Assets Engineering 329 (2), 16 (2018)

9. A. N. Subbotin, Izvestiya Tomsk Polytechnic University 4, 23 (2008)

10. R. N. Kulesh, A. S. Mazanik, A. N. Subbotin, Izvestiya Tomsk Polytechnic University 4, 25 (2014)

11. J. A. Oraz, I. E. Korzilova, A. N. Ermolaev, S. A. Khaustov, A. Y. Dolgih, MATEC Web Conf. 92, 01001 (2016)

12. A. Gómez, N. Fueyo, L. I. Díez, Appl. Therm. Eng. 28, 532 (2008)

13. M. Pezo, V. D. Stevanovic, Z. Stevanovic, Int. J. Heat Mass Tran. 49, 1214 (2006)

14. A. Habibi, B. Merci, G. J. Heynderickx, Comput. Chem. Eng. 31, 1389 (2007)

15. C. K. Weng, A. Ray, X. Dai, Appl. Math. Model. 20, 501 (1996)

16. V. R. Sabanin A. A. Starostin, A. I. Repin, A. I. Popov, Therm. Eng. 64 (2), 151 (2017)

17. A Behbahaninia., M. Bagheri, R. Bahrampoury. Appl. Therm. Eng. 30, 2378 (2010)

18. P. S. Gergelizhiu, S. A. Khaustov, R. B. Tabakaev, P. Y. Novoseltsev, A. V. Kazakov, A. S. Zavorin, Proc. of 2014 Int. Conf. on Mechanical Engineering, Automation and Control Systems, 109804 (2014) 